\title{
Neurosurgical Management of Pott's Puffy Tumor in an Obese Adolescent with Asthma: Case Report with a Brief Review of the Literature
}

Guilherme G. Podolsky-Gondim ${ }^{1}$, Marcelo V. Santos ${ }^{2}$, Vinícius M. Carneiro ${ }^{1}$, Lucas Pires Augusto ${ }^{3}$, Romilto Da Costa Pacheco Neto ${ }^{2}$, Ricardo Santos de Oliveira ${ }^{2}$

1. Division of Neurosurgery, Department of Surgery and Anatomy, Ribeirão Preto Clinics Hospital, Ribeirão Preto Medical School, University of São Paulo, Ribeirão Preto, BRA 2. Division of Pediatric Neurosurgery, Department of Surgery and Anatomy, Ribeirão Preto Clinics Hospital, Ribeirão Preto Medical School, University of São Paulo, Ribeirão Preto, BRA 3. Division of Pediatric Neurosurgery, Department of Surgery and Anatomy, Ribeirão Preto Clinics Hospital, Ribeirão Preto Medical School, University of São Paulo, Ribeirao Preto, BRA

Corresponding author: Guilherme G. Podolsky-Gondim, podolsky@usp.br
Received 06/13/2018

Review began 06/15/2018 Review ended 06/17/2018 Published 06/19/2018

๑) Copyright 2018

Podolsky-Gondim et al. This is an open access article distributed under the terms of the Creative Commons Attribution License CC-BY 3.0., which permits unrestricted use, distribution, and reproduction in any medium, provided the original author and source are credited.
Categories: Pediatrics, Neurosurgery

Keywords: frontal sinusitis, pott puffy tumor, epidural abscess

\section{Introduction}

More than 250 years have passed since the British surgeon Sir Percival Pott initially described what is now known as the Pott's puffy tumor, a subperiosteal abscess of the frontal bone presenting as a progressive forehead edema secondary to frontal osteomyelitis following frontal sinusitis [1-2]. Although a rare clinical complication in the modern area of antibiotics, there are still recent reports of cases in adult and pediatric patients [1-13].

We describe herein a case of a male adolescent diagnosed with a Pott's puffy tumor with an epidural abscess in addition to the classical frontal subperiosteal abscess and discuss the literature regarding the diagnosis and treatment of this pathology.

\section{Case Presentation}

A 14-year-old adolescent was referred to the emergency department (ED) for a neurosurgical consultation with a chief complaint of progressive left forehead bulging in the last three weeks. His parents reported that the patient was seen by a general physician in another institution at the beginning of the symptoms and received a course of oral antibiotics (amoxicillin and clavulanic acid) for the past 21 days. Nevertheless, due to a worsening of the edema on his forehead, CT and ultrasound scans of the head were performed and the patient was referred for a neurosurgical assessment. The patient had a history of asthma, with the daily use of nasal formoterol and budesonide and the chronic use of oral prednisone monthly for up to two to three days. He had recently been referred for a pediatric endocrinological evaluation due to marked obesity (body mass index of 45) with Acanthosis nigricans. There were no reports of head trauma, previous surgery, or hospital admissions.

Upon physical examination, marked obesity was noted with Acanthosis nigricans and a compressible softtissue swelling in the left forehead (Figure 1), with an otherwise unremarkable neurological exam. 


\section{Cureus}

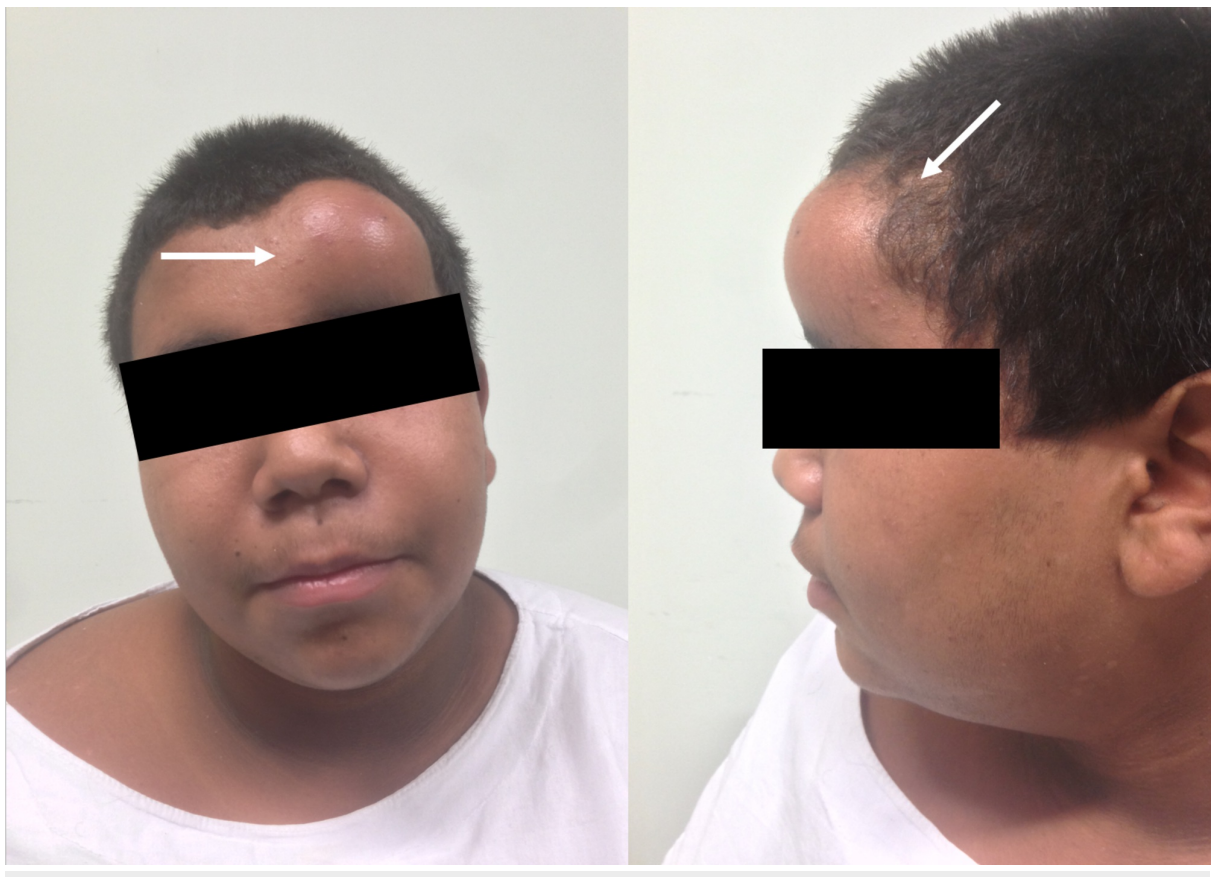

\section{FIGURE 1: Preoperative photographs}

Note the soft-tissue swelling in the left frontal area (white arrow).

Radiological imaging with contrast-enhanced CT and gadolinium-enhanced magnetic resonance scans of the head were performed, showing extensive frontal-ethmoidal sinusitis with bone erosion of the frontal sinus internal and external walls and an epidural and periosteal left-frontal mass with capsular contrastenhancement suggestive of an abscess (Figures 2-4).

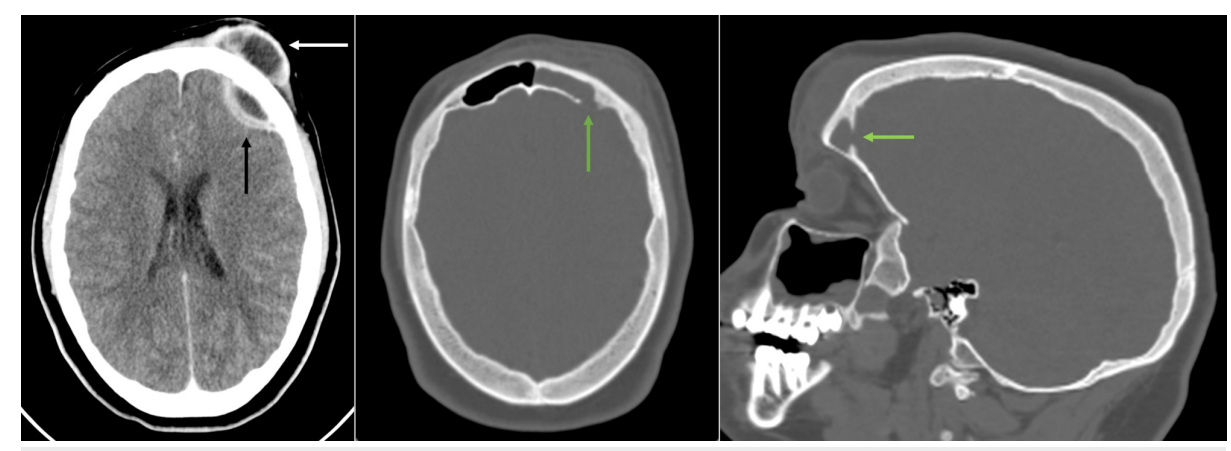

FIGURE 2: Preoperative CT scans of the head

Left: Contrast-enhanced axial computed tomography (CT) scan with epidural (black arrow) and frontal periosteal (white arrow) enhancing mass compatible with an abscess. Middle: Note the bony erosion of the internal wall of the frontal sinus (green arrow) seen on the axial bone window CT scan. Right: Parasagittal imaging of the bony erosion (green arrow) seen in the middle scan. 


\section{Cureus}
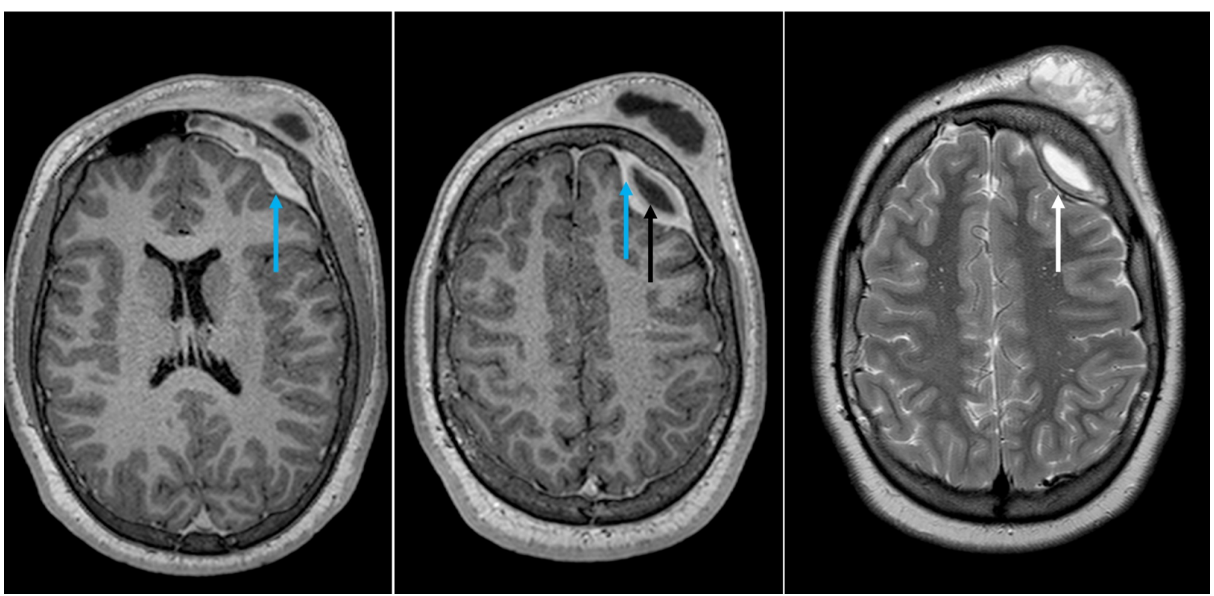

FIGURE 3: Preoperative MRI of the head: axial reconstruction

Preoperative gadolinium-enhanced MRI of the head. Left and middle: An epidural contrast-enhanced capsule (blue arrow) with a center with low signal on a T1-weighted sequence was seen (black arrow), compatible with an abscess. Right: Note the dura mater (white arrow) interposed between the left frontal lobe and the epidural mass with a hyperintense signal on T2-weighted sequence.

MRI: magnetic resonance imaging

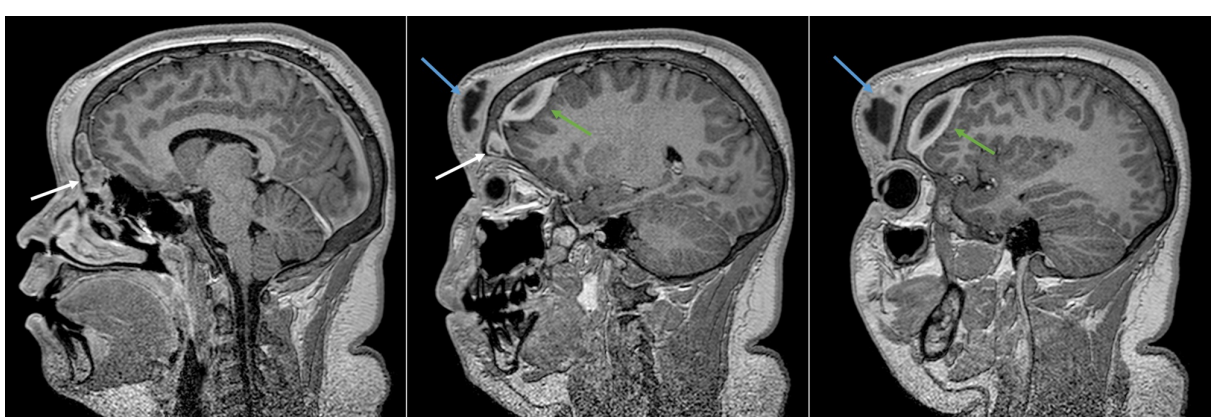

FIGURE 4: Preoperative MRI of the head: parasagittal reconstruction

Parasagittal slices of the preoperative gadolinium-enhanced magnetic resonance imaging (MRI) of the head. In the left and middle images, there is an enhancing lesion filling the left frontal sinus (white arrow) and extending both epidurally (middle and right images - green arrow) and to the periosteum (blue arrow).

After parental consent, the patient was submitted to surgery with a bicoronal skin incision, exposing the infiltrated subcutaneous tissue. After a left frontal craniotomy, an epidural mass compatible with an abscess was found (Figure 5).
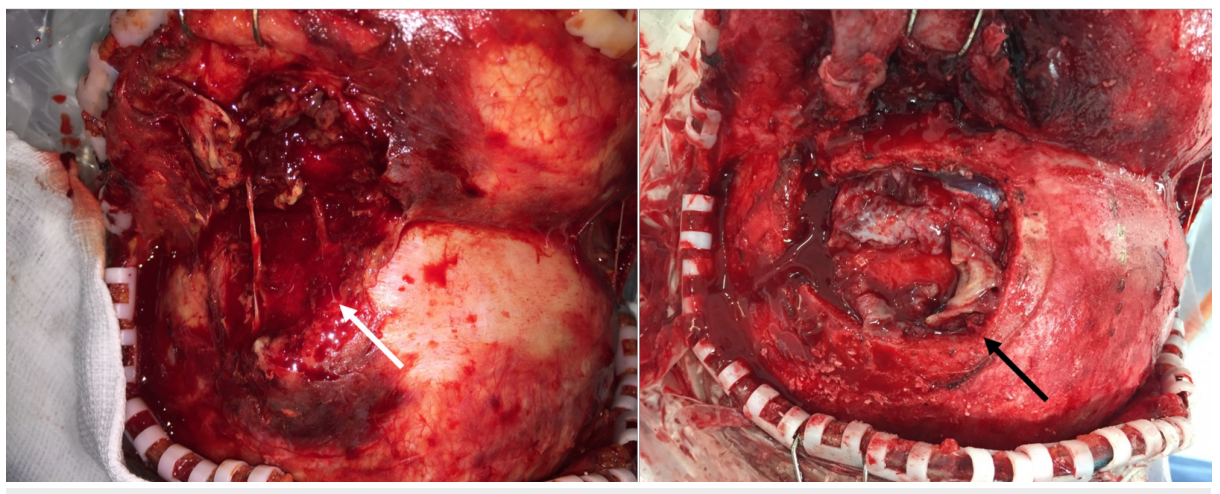

\section{FIGURE 5: Intraoperative photographs}

Intraoperative photograph after the bifrontal flap was reflected anteriorly, demonstrating the extensive periosteal and subcutaneous soft tissue compromise (white arrow) and, after left-side frontal craniotomy, 


\section{Cureus}

showing the epidural mass and debris (black arrow).

The left frontal sinus was cranialized with an exenteration of the mucosa in order to avoid late complications, such as mucocele formation, and after an extensive removal of debris and specimen sampling, a pedicled pericranium flap was inserted in the frontal sinus drainage pathway and the bone flap was fixed (Figure 6).

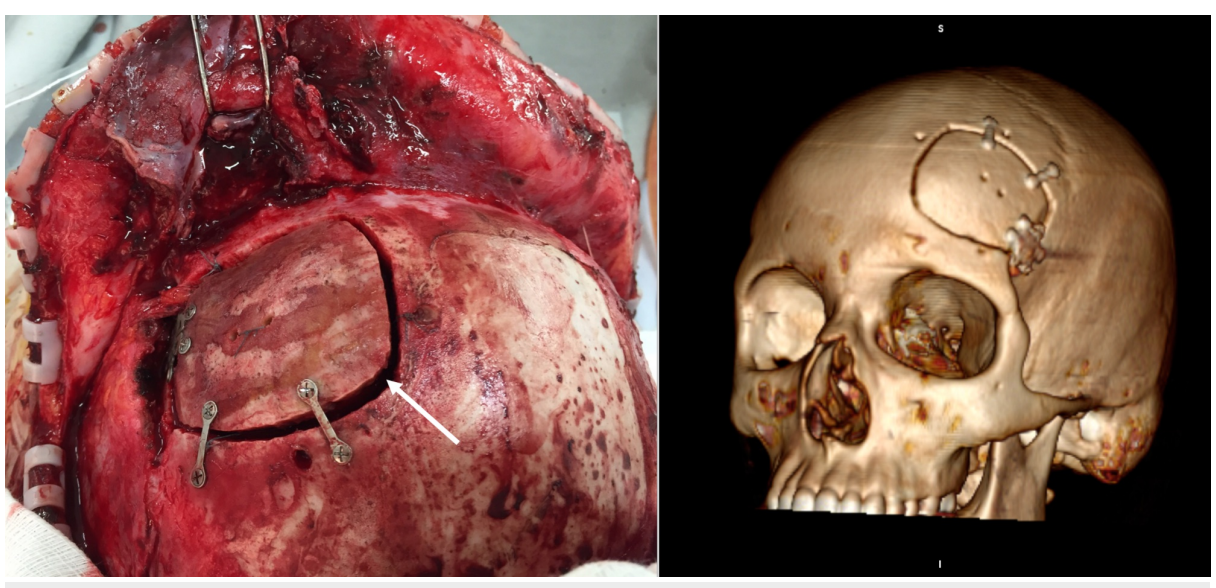

\section{FIGURE 6: Final surgical aspect of the craniotomy}

Left: Intraoperative view of the final surgical aspect after fixation of the bone flap (white arrow) with titanium plates and screws. Right: 3D reconstruction of the postoperative computed tomography (CT) scan of the head.

The postoperative period was uneventful, and the patient was submitted to a four-week course of intravenous ceftriaxone/ oxacillin/metronidazole followed by four weeks of oral amoxicillin with clavulanic acid after discharge, as discussed with the Institutional Commission for Control of Infectious Diseases, based on the favorable clinical response of the patient. A post-operative contrast-enhanced CT scan showed no signs of complications or residual lesions (Figure 7).

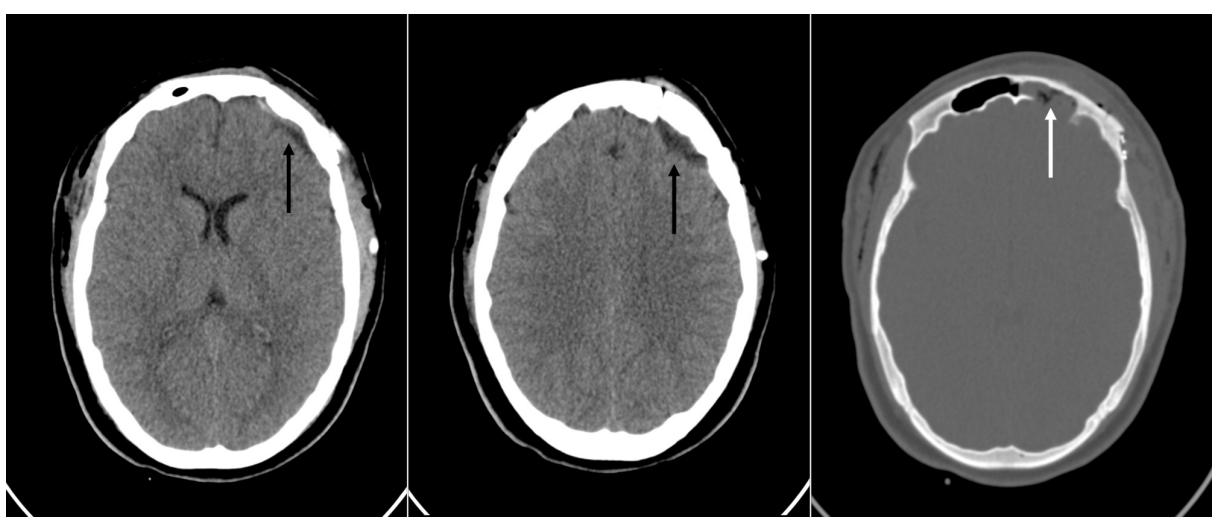

\section{FIGURE 7: Postoperative CT scans of the head}

Postoperative contrast-enhanced computed tomography (CT) of the head. Note in the left and middle images the absence of a residual lesion (black arrow) on the axial slices with the brain window and, in the right image, with the bone window, the post-operative cranialization of the left frontal sinus with the filling of the cavity with a periosteum graft (white arrow).

The culture of the intraoperative lesion was positive for Peptostreptococcus species. The patient was followed in the pediatric neurosurgical outpatient clinic, with no signs of recurrence. However, 18 months after surgery, the patient was referred for an otorhinolaryngologist consultation following chronic sinusitis.

\section{Discussion}

Pott's puffy tumor is a rare entity; however, there is an increasing number of reports in the medical 
literature in recent years, particularly in the pediatric population, which may be attributed to delayed or inadequate treatment of frontal sinusitis [2]. Clinical signs include, in the majority of cases, frontal swelling, fever, and headache [2-4]; however, less frequently, there are reports of neurological symptoms, such as focal seizures, cranial nerve or motor deficits [5], a sinocutaneous fistula [6], and eyelid necrosis [7].

Differential diagnosis for any swelling in the forehead includes, but is not limited to, soft-tissue infection, such as carbuncle and infected sebaceous cyst; benign tumors, such as dermoid cysts, lipomas, intraosseous lipomas, lipoblastomas, frontal sinus mucoceles, and superficial temporal artery pseudoaneurysms, and, finally, malignant tumors, such as metastases or aggressive frontal meningiomas [8-9].

The diagnostic workup should include contrast-enhanced CT scan with brain and bony sequences to investigate the presence of an epidural or subdural abscess and to estimate the extent of bone erosion. Also, gadolinium-enhanced MRI may help define the involvement of brain parenchyma or dura mater [3]. Pneumocephalus also may be found [10]. Ultrasound imaging of the forehead may assist in the initial radiological investigation and to guide needle specimen collection for culture [11].

Common causative organisms are Streptococcus species (alpha- and beta-hemolytic Streptococci and Peptostreptococci), Hemophilus influenza, anaerobic bacteria, such as Fusobacterium species and Bacteroides species, and, less commonly, Staphylococcus aureus and Enterococci species [2].

In our case, the patient was referred after an initial clinical suspicion of soft-tissue frontal infection and was shown by the CT and MRI scans to present an epidural abscess associated with frontal osteomyelitis with the erosion of the inner table of the left frontal sinus, although no neurological symptoms were present upon admission. Also, in our case, we wondered if the chronic use of corticoids due to asthma and the association of obesity had any relation with the occurrence of this rare complication; however, we couldn't find any previous reports of similar clinical scenarios.

After diagnosis, the management should include broad-spectrum antibiotics and the surgical evacuation of the abscess, which may be performed via open surgery [1-2,7] or, more recently, through minimally invasive techniques (i.e. frontal sinus endoscopic surgery) [12-13]. There are reports of conservative treatment with broad-spectrum antibiotics without surgery; however, a close follow-up with repeat imaging should be considered in these cases [3].

Prognosis, in general, is favorable, even if neurological symptoms are present upon admission; obviously, prompt recognition and treatment are mandatory for successful outcomes.

\section{Conclusions}

Although sometimes depicted as a rare occurrence in the age of broad-spectrum antibiotics, Pott's puffy tumor must be suspected as a serious complication of frontal sinusitis in both pediatric and adult patients. Early clinical suspicion, diagnosis, and the treatment of the frontal sinusitis and its complications with surgery and broad-spectrum intravenous antibiotics bring up the possibility of good recovery.

\section{Additional Information \\ Disclosures}

Human subjects: Consent was obtained by all participants in this study. Conflicts of interest: In compliance with the ICMJE uniform disclosure form, all authors declare the following: Payment/services info: All authors have declared that no financial support was received from any organization for the submitted work. Financial relationships: All authors have declared that they have no financial relationships at present or within the previous three years with any organizations that might have an interest in the submitted work. Other relationships: All authors have declared that there are no other relationships or activities that could appear to have influenced the submitted work.

\section{References}

1. Salomão JF, Cervante TP, Bellas AR, Boechat MC, Pone SM, Pone MV, de A. Pereira B: Neurosurgical implications of Pott's puffy tumor in children and adolescents. Childs Nerv Syst. 2014, 30:1527-1534. 10.1007/s00381-014-2480-X

2. Kombogiorgas D, Solanki GA: The Pott puffy tumor revisited: neurosurgical implications of this unforgotten entity. Case report and review of the literature. J Neurosurg. 2006, 105:143-149. 10.3171/ped.2006.105.2.143

3. Bhalla V, Khan N, Isles M: Pott's puffy tumour: the usefulness of MRI in complicated sinusitis . J Surg Case Rep. 2016, 2016:1-3. 10.1093/jscr/rjw038

4. Akiyama K, Karaki M, Mori N: Evaluation of adult Pott's puffy tumor: our five cases and 27 literature cases . Laryngoscope. 2012, 122:2382-2388. 10.1002/lary.23490

5. Haider HR, Mayatepek E, Schaper J, Vogel M: Pott's puffy tumor: a forgotten differential diagnosis of frontal swelling of the forehead. J Pediatr Surg. 2012, 47:1919-1921. 10.1016/j.jpedsurg.2012.06.031

6. Terui H, Numata I, Takata Y, Ogura M, Aiba S: Pott's puffy tumor caused by chronic sinusitis resulting in sinocutaneous fistula. JAMA Dermatol. 2015, 151:1261-1263. 10.1001/jamadermatol.2015.0874 


\section{Cureus}

7. Low SA, Hussain A, Gill HS, Monteiro E, Liu ES: Pott's puffy tumour presenting as a necrotic eyelid lesion . Can J Ophthalmol. 2017, 52:25-28. 10.1016/j.jcjo.2016.06.009

8. Sabatiello M, Vanhooteghem O, Mostinckx S, De La Brassinne M: The Pott's puffy tumor: an unusual complication of frontal sinusitis, methods for its detection. Pediatr Dermatol. 2010, 27:406-408. 10.1111/j.1525-1470.2010.01182.x

9. Shemesh AJ, Panebianco NL, Chen AE: An uncommon complication of sinusitis in a young adolescent . Pediatr Emerg Care. 2015, 31:531-532. 10.1097/PEC.0000000000000491

10. Sugiyama A, Kobayashi M, Moriishi H, Tanaka H, Mitsuyoshi R, Matsunaga T, Kuwabara S: Pneumocephalus associated with Pott's puffy tumor. J Neurol Sci. 2016, 362:196-197. 10.1016/j.jns.2016.01.056

11. Weinberg B, Gupta S, Thomas MJ, Stern H: Pott's puffy tumor: sonographic diagnosis . J Clin Ultrasound. 2005, 33:305-307. 10.1002/jcu.20130

12. van der Poel NA, Hansen FS, Georgalas C, Fokkens WJ: Minimally invasive treatment of patients with Pott's puffy tumour with or without endocranial extension - a case series of six patients: our experience. Clin Otolaryngol. 2016, 41:596-601. 10.1111/coa.12538

13. Leong SC: Minimally invasive surgery for Pott's puffy tumor: is it time for a paradigm shift in managing a 250-year-old problem?. Ann Otol Rhinol Laryngol. 2017, 126:433-437. 10.1177/0003489417698497 